\title{
Language-Games and Artistic Styles
}

Wittgenstein introduces the idea of language-games to address the problems of truth and falsehood, the agreement of propositions with reality, and the nature, or natures, of assertions, assumptions, and the very act of questioning. ${ }^{1}$ As there has been considerable disagreement over the definition and use of language-games, as well over the specific features of language and linguistic activity that they are designed to make salient, let us begin with Wittgenstein's own introductory remarks to this analytical tool. He says, "The study of language-games is the study of primitive forms of language or primitive languages." 2 Of course, by the time he'd developed this tool ${ }^{3}$ he no longer believed that actual discourse was simply a rather messy affair that had to be cleaned up (that is, formalized into logical perfection) as he did earlier while working under the influence of Bertrand Russell, but rather that ordinary language

1. See the introductory discussion of this idea from which this list of issues is drawn, in Ludwig Wittgenstein, The Blue and Brown Books (Oxford: Basil Blackwell, i958), pp. 17-20.

2. Ibid, p. 17 .

3. That is to say, at this stage, Wittgenstein no longer regarded the referential perfection sought after in Tractatus Logico-Philosophicus as an ideal toward which philosophy should aspire. 
was in fact extraordinarily complex, and that those intrinsic complexities are of a magnitude to obscure if not preclude our view of some of the fundamental features of language as it is used. Thus, he says, language-games are "ways of using signs simpler than those in which we use the signs of our highly complicated everyday language," and through language-games we can see, clearly if only partially, the complex "forms of thinking," as they appear in "primitive forms of language," in a very advantageous position, that is, "without the confusing background of highly complicated processes of thought." And indeed the remarkable thing about employing language-games within larger investigations into the nature of language is that inside the linguistic microcosms of these primitive forms of language "the mental mist which seems to enshroud our ordinary use of language disappears."

Naturally, any strategy that promises clarity is worth pursuing. But this must be approached in stages: the first is to look at Wittgenstein's own development of the language-game strategy in connection with the problem of linguistic meaning; the second is to identify the features of language this strategy renders evident; the last is to assess the results of an analogical employment of language-games in the arts and to see if any of the mist enshrouding the concept of artistic meaning has in fact disappeared.

The Concept of a Language-Game

Despite the unfortunate connotations of the word "game," a "language-game" is neither trivial ("only a game") nor primarily concerned with rule-following (playing "strictly according to the rules"). That language-games are not trivial can, of course, be seen only at the end of this discussion. That they are not concerned with the laying bare of the rule-governed nature of natural language can be addressed, at least in part, presently. 
It is significant that Wittgenstein does not mention rules when introducing the idea of the language-game. Following the remark about clearing the mist, he says, "We see activities, reactions, which are clear-cut and transparent." And in the fully mature use of this idea in the early sections of Philosophical Investigations, it is the general idea of the meaning of a word, and the corresponding attempts to capture that meaning theoretically, which are identified as the source of the mist. Already looking back to section 1 of Philosophical Investigations and the much-discussed "five-red-apples" case, in which he imagines sending a person with a shopping list with the words "five red apples" written on it to a shopkeeper (who acts in a way, or uses the words in such a way, that no question of the meaning of the word "five" arises), ${ }^{4}$ Wittgenstein says, "If we look at the example in Section 1, we may perhaps get an inkling how much this general notion of the meaning of a word surrounds the working of language with a haze which makes clear vision impossible." Making it very clear that it is indeed clarity he is after, he continues, "It disperses the fog to study the phenomena of language in primitive kinds of applications in which one can command a clear view of the aim and functioning of the words." ${ }^{5}$ The topic of the aim and function of words is remote from the study of the rules according to which words may be uttered. ${ }^{6}$ And it is a clear view of that aim and that function

4. Ludwig Wittgenstein, Philosophical Investigations, 3d ed., trans. G.E.M. Anscombe (New York: Macmillan, 1953), sec. 1; a preliminary sketch for this example can be found in The Blue and Brown Books, pp. 16-17.

5. Philosophical Investigations, sec. 5 .

6. I use Wittgenstein's phrase "aim and function" throughout this discussion, but by it I do not mean that the speaker deliberates on the aim of a word either preceding its use or as it is used. A lung, for example, has a function, and, in a sense, an "aim", but not where its employment requires deliberation or intention; I discuss the removal of ratiocination from center stage in Chapter 2. My use of "aim" might, incidentally, be characterized as Aristotelian; at the beginning of the Nicomachean Ethics Aristotle identifies happiness as the aim of all human activity, but Aristotle still could not have meant that all human 
within the context of the language-game under consideration which is desired. In the discussion of the case of the shopkeeper and the apples, the interlocutor tries, if only indirectly, to bring into consideration the question of rules, by asking, "But how does he know where and how he is to look up the word 'red' and what he is to do with the word 'five'?" Wittgenstein's response refocuses the issue on linguistic aim and function, saying, "Well, I assume that he acts as I have described." And he adds at this very early point the remark that, as we shall see, is of the utmost importance to our understanding of languagegames: "Explanations come to an end somewhere." The insistent interlocutor responds, "But what is the meaning of the word 'five'?" Wittgenstein, resisting the encroaching haze, says at this point simply, "No such thing was in question here, only how the word 'five' is used."

What shall we, then, expect so far? The language-game strategy will (1) make readily visible the aims and the functions of words; (2) show us the manageably miniscule context in which those words have aims and functions; (3) systematically prevent the fog-bound general question of the meaning of a word from arising; (4) disallow questions extraneous to the smaller and circumscribed context of the language-game, for example, the interlocutor's question pertaining, if only indirectly, to the rules under which the shopkeeper uses "five"; and (5) make us sensitive, in a way that we could not be in the extraordinarily complex contexts of actual language, to the lines demarcating the limits of those language-games and to verbal and conceptual transgressions of those limits. For the same reasons the employment of the language-game strategy will make us sensitive

action is immediately subsequent to deliberation about the employment of means to the end of happiness.

7. Although this remark does unfortunately create the impression of an underlying behaviorism and thus appears to support a common misunderstanding of Wittgenstein's antimentalism, it in fact makes salient, not actual behavior, but rather the action of a person within a context. 
to every incremental expansion of the context in a way we could never be in full-scale discourse.

Let us pursue these matters. We are familiar with the idea that the meaning of a word is uniform and generally accurate regardless of local linguistic detail; Wittgenstein quotes $\mathrm{Au}-$ gustine's Confessions to this effect as the opening move of Philosophical Investigations. ${ }^{8}$ In that view, language has an essence, words function as names, sentences or propositions are constituted by combining such names, and-very generally-the meaning of a word is the object for which it stands. With this background in mind Wittgenstein turns to the shopkeeper with the slip marked "five red apples." At a glance we can see, at least within this narrow context, that Augustine's conception is already in trouble. "Apples" might conform to this theory of meaning, although "apple" would be better. "Red" is more troublesome: does it mean what it stands for? Again, we might save the Augustinian definition of meaning, but only by going far beyond this language-game to speak of qualities, properties, and so on. And "five" is most troublesome, because its meaning cannot be derived from just looking at the apples. And in the middle of this theory-threatening introductory game Wittgenstein mentions that "it is in this and similar ways that one operates with words." "Ways," after all, is plural; and "naming" is only one operation performed with words. We have, inside this very narrowly delimited game, seen ostensive naming replaced by the more powerful idea of linguistic aim and function.

This replacement is further shown in the equally well known and even more discussed language-game of the builders, who work within the linguistic microcosm that includes only "block,". "pillar," "slab," "beam"; here the meaning of the word "Slab!" could not be only the object to which "slab" refers. But the

8. It is worth remembering here that Wittgenstein does not for one moment agree with Augustine's position; indeed, he found it especially useful as a point of departure because he found it astonishing that so great a mind could have held it. 
replacement is accomplished with greater finesse in section 6 , in which Wittgenstein imagines children being taught the language of the builders. Here we have a teacher directing the child's attention to the slab, pointing at it, and saying "slab." Doesn't this vindicate the Augustinian conception of meaning? Isn't this a clear case of the meaning of a word being the thing for which it stands? Decidedly not, for to formulate the question itself is to transgress the limits of the game. Wittgenstein says, parenthetically, "I do not want to call this 'ostensive definition', because the child cannot as yet ask what the name is." That is to say, within this linguistic microcosm, the question, "What is that thing called?" that we might presume the child to have asked not only was not, but in fact could not, be asked; we are, again, inside the invented language-game "consisting of the words 'block', 'pillar', 'slab', 'beam' " (PI, sec. 2). Nevertheless, one might insist, on behalf of Augustine and the possibility of a general conception of meaning, that the case does "establish an association between the word and the thing" (PI, sec. 6). It may well be true, as Wittgenstein readily admits, that such an association is formed, and thus that uttering the word is like "striking a note on the keyboard of the imagination"; however, the point is that the function of the word "slab," within this rarified pedagogical language-game, is not to evoke a mental image. The Augustinian element, if present, still cannot capture the meaning. Indeed, one operates with words, and such operations, like moves in a game, are made possible by the context in which the move is made. And to move, to operate, is to act. Thus Wittgenstein says, in section 7 , "I shall also call the whole, consisting of language and the actions into which it is woven, the 'language-game'." Many have thought of Wittgenstein's use of this analytical tool that, if it is a game, then one must play according to the rules. It appears that we would be closer to the intended use if we said, as Wittgenstein does elsewhere, "This game is played!"9

9. This, of course, reinforces the idea of a focus on action within a context 
An increased sensitivity to the expansion of a language-game is another of the rewards of this strategy. Wittgenstein demonstrates this by adding, to the language-game of the builders, the designations A, B, C, and D; the words "there" and "this"; and a number of color samples. In this slightly expanded language-game, one builder might say to another, 'D-slab-there," while showing him a color sample and pointing to a particular location. With these few additions, a language-game has been created that is much more complex than its predecessor. The range of possible misunderstandings has been similarly increased. First, as we have seen before, the ostensive definition here of "A, B, C, and D" will not suffice, because an assistant could believe himself to be in control of these words having been shown one, two, three, and then four slabs, and then, on hearing "C-beam," find himself utterly lost. Worse, he might similarly equate "this" with a particular shape, say that of the block, and find himself utterly lost when it is used in conjunction with any other shape. The importance of aim and function - that is, use - is made clearer in the case of "there." Indeed, Wittgenstein puts the question as follows: "Are 'there' and 'this' also taught ostensively?-Imagine how one might teach their use" (PI, sec. 9). In fact, trying to teach the meaning of the word "there" ostensively would produce either ineradicable frustration, or perhaps to a different sensibility, unbounded hilarity, since anything pointed to is in fact "there." On ostension, Wittgenstein adds, "One will point to places and thingsbut in this case the pointing occurs in the use of the words too and not merely in learning the use" (PI, sec. 9). This last point is as powerful as it is condensed. The individual words may indeed be taught through ostension, but such acts of ostension, such "pointings," will in fact occur within the context of actual linguistic practice. The definition of the word, and the learning of its use, is not prior to the language-game inside which that

rather than on mere outward behavior; see also Philosophical Investigations, secs. $654^{-5} 5^{6}$. 
word functions. And, indeed, it may well, and probably will, have multiple functions and uses, but this multiplicity will be determined by the context, the larger game, within which the word operates.

Nevertheless, one might still insist, in a way consistent with the traditional search for a general theory of meaning, that a word, even if taught ostensively within contextual limits, within a game with autonomous and internally generated ranges of possible moves, must have a meaning, that it must signify above and beyond any particular game. Thus in section 10 Wittgenstein entertains the question of what the words of the microcosmic language signify, and realizes that the significance has already been shown, in the use, and that the use has been described. ${ }^{10}$ If we insist that "slab" signifies this object and not (say, to correct a mistake) that block-shaped one over there, then we have done something that looks like directly describing the significance of "slab." But this too is not, after all, contextfree referential meaning, "because the kind of 'referring' this is ... is already known" (PI, sec. 10). Thus the ability to state that the word "slab" signifies that particular object is rendered possible within the game; in this case to correct an error also made possible within it. And numerous further mistakes or possible misunderstandings within this microcosm can be corrected in a very similar way, that is, through ostensive pointing and "labeling." But it does not follow from the fact of the similarity of the descriptions of the uses of these few words that the aims and functions of the words themselves are similar.

The above observation is high on the list of philosophically relevant but easily forgotten facts, and it is made all the more perilously forgettable by the fact that words, "when we hear them spoken or meet then in script or print" $(P I$, sec. 11), exhibit a misleadingly uniform appearance. Taken together,

10. This section thus houses an implicit backward glance at the Tractatus, in which the comparison of the later with the earlier view further reinforces the position that the meaning has already been shown in the use. 
words have a unitary look, their applications and functionstheir powers-within contexts are obscured, and the similarity of the descriptions of their uses make them appear further alike. But because of the already multifarious ways we see language operating inside this slightly expanded builders' language-game, this uniformity is utterly fallacious, a mirage produced by superficial linguistic appearance. For these words and their functions are "as we see ... absolutely unlike" (PI, sec. 10). From this vantage point it is then perhaps less puzzling than usual why Wittgenstein says, in section 13, "When we say 'Every word in language signifies something' we have so far said nothing whatever." Because of the context-free generality of this remark, I believe that Wittgenstein meant quite literally nothing. To be more precise, "Every word in language signifies something" is an empty statement because it can only be made above and beyond any language-game or context within which moves, or aims and functions, are possible. Of course, it could mean something, but only in a context in which, as Wittgenstein adds to this striking claim, "we have explained exactly what distinction we wish to make," for example, trying to explain to someone why Lewis Carroll's phrase "slithy toves" is in fact nonsense. A familiar Wittgensteinian slogan is that a word has meaning only in the context of a sentence. The claim that we have, in saying that every word signifies something, so far said nothing can be taken to suggest that a sentence has meaning only within a context. But with this thought we should now turn to a further consideration of what is perhaps the central reward of employing the language-game strategy, the increased sensitivity to the limits of the game.

\section{Linguistic and Artistic Microcosms}

It is easy to say and difficult to show that language-games, as employed by Wittgenstein, are internally circumscribed, and are thus autonomous, and that they also generate their own 
range of possible moves without transgressing their own boundaries, and are thus self-sufficient. ${ }^{11}$ But Wittgenstein begins the task of showing the autonomous nature of languagegames in section 19, in which he asks whether the call "Slab!" from the nonexpanded builders' language is a sentence or a word. If it is a word, then it certainly does not possess the same meaning as our word "slab" in ordinary language. Focusing on the instrumental function shows that "Slab!" is in that microcosmic language a call. And if this call "Slab!" is a sentence, then it is not, nor could it be, an instance of our elliptical sentence "Slab!" which is a truncated version of "Bring me a slab!" because there is "no such sentence" in this languagegame (PI, sec. 19). Indeed, our "Bring me a slab!" cannot even be used to articulate the meaning of their "Slab!" because our sentence is not a possible maneuver within the narrowly described limits of their language.

At this juncture the debate with the interlocutor produces heat as well as light, and we must follow it closely. Wittgenstein adds to the above the seeming afterthought (which actually leads to his point), "But why should I not on the contrary have called the sentence 'Bring me a slab!' a lengthening of the sentence 'Slab!'?," thus suggesting a kind of linguistic relativity where neither their nor our language has Archimedean fixed points of meaning such that their locutions really mean some other in ours. They are independent and mutually autonomous. The interlocutor answers, "Because if you shout 'Slab!' you really mean: 'Bring me a slab!', here illustrating the naive belief in a fixed point of linguistic reference, that any elucidation of their meaning will proceed in terms of our meaning. Wittgenstein asks, "But how do you do this: how do you mean

11. A helpful discussion of the self-sufficiency of language-games can be found in J. F. M. Hunter, " 'Forms of Life' in Wittgenstein's Philosophical Investigations," American Philosophical Quarterly 5 (October 1968): 233-43; reprinted in Essays on Wittgenstein, ed. E. D. Klemke (Urbana: University of Illinois Press, 1971). 
that while you say 'Slab!'? Do you say the unshortened sentence to yourself?" Within the context of this philosophical disagreement this argumentative salvo directed against the interlocutor is aimed directly at the presumed belief in the separability of meaning from saying, or of, in short, the conceptual prerequisite for the very kind of general theory of meaning with which we began. And showing that the function of this utterance is to explode that myth, he adds, "And why should I translate the call 'Slab!' into a different expression in order to say what someone means by it?" We might well answer that we should so translate because after all the separate utterances mean the same, although one occurs in the builders' linguistic microcosm and the other in our larger language, which would be reasonable if meaning and saying were separable. Wittgenstein does not delay in countering that answer: "... and if they mean the same thing — why should I not say: "When he says "slab!" he means "slab"?" "

Of course, this translation, as mere repetition, is obviously worth precisely nothing as an explanation of meaning-yet such reduplication is what the interlocutor's demands, if fulfilled, seem to generate. And again suggesting a mutual autonomy between language-games, Wittgenstein asks, "Again, if you can mean 'bring me the slab', why should you not be able to mean 'Slab!'?" In what must be some admixture of desperation and exasperation, the interlocutor answers, "But when I call 'slab!', then what I want is, that he should bring me a slab!" And now placing before the eyes of the reader the inescapable absurdity of the interlocutor's mentalistic conception of the meaning the word is believed to have, Wittgenstein answers, "Certainly, but does 'wanting this' consist in thinking in some form or other a different sentence from the one you utter?" And must not someone who views linguistic meaning as something above and beyond the word, the sentence, and the context share the view of the interlocutor? If he views linguistic meaning as something that is fixed outside the language-game within 
which it allegedly later operates, and as something prior to its employment within the specific moves of a game, then indeed he is in perfect harmony with the interlocutor. Wittgenstein, however, rejects this view, claiming rather that meanings are native residents of their contexts, of particular regions of language.

In conjunction with the autonomy of language-games there exists the issue of self-sufficiency or the idea that possible moves are internally generated and that language-games consequently define their own boundaries. And, of course, if the possible moves of the language-game are equivalent to what, cumulatively, that language-game has a capacity to express, and if the boundaries or limits of a language-game, as the far reaches of those moves, demarcate the line between the linguistically expressible on the one side and the unintelligible, ineffable, or unsayable on the other, then these features of Wittgenstein's strategy ought not to come as a surprise. ${ }^{12}$

A fundamental question at this point is, when a speaker in a linguistic microcosm utters an expression within it, whether the other available utterances of that microcosm must be in some sense present to the mind of the utterer. Wittgenstein's own answer to this question casts much light on his larger concept of language-games. If a builder says, "Bring me a slab," he could, the interlocutor suggests in section 20, "mean this expression as one long word corresponding to "Slab!" The interlocutor is of course looking back to the previous discussion, but Wittgenstein moves ahead by asking, "How does one usually mean it?" and answers his own question by saying that when we use it in contrast with other sentences available within this expanded builder's language, such as "Hand me a slab," or "Bring him a slab," or "Bring two slabs," and so on, then we

12. The strict demarcation of the bounds of the intelligible is of course the objective of the Tractatus. A discussion of the attempt to build an aesthetic theory that foundation can be found in my "Art and the Unsayable: Langer's Tractarian Aesthetics," British Journal of Aesthetics 24 (Autumn 1984): 325-40. 
would say that we mean the initial command as four words. But the important point here rests not with the counting of words; it is rather that we use those four words, within the expanded linguistic microcosm, "in contrast with sentences containing the separate words of our command in other combinations." We are thus here introduced to the idea of multiple combinations and permutations resident within the languagegame, an idea that lends content to the larger conception of the self-sufficiency of language-games.

Immediately germane, however, are the interlocutor's following questions: "But what does using one sentence in contrast with others consist in? Do the others, perhaps, hover before one's mind? All of them? And while one is saying the one sentence, or before, or afterwards?" These questions are grounded in the very sort of context-free linguistic mentalism that Wittgenstein is opposing or, better, precluding; and illustrating the philosophical practice of looking to see, he replies, "No. Even if such an explanation rather tempts us, we need only think for a moment of what actually happens in order to see that we are going astray here." To clarify what for our immediate concern is most important, the self-sufficiency of language-games, that is, how they generate their own expressive or locutionary possibilities, he adds, "We say that we use the command in contrast with other sentences because our language contains the possibilities of those other sentences." Here Wittgenstein has moved from context-free mentalism, where minds hold expressive potentialities irrespective of context, to the context of the language-game itself. The limits of the expressible are not mentally or solipsistically drawn; they are a function of the possible moves of the game. The builder, who sees clearly this multiplicity of expressive possibilities, the web of "Hand or Bring, me or him, a or two, slab or slabs," and so on, has what Wittgenstein refers to a bit later in the same section as "a mastery of this language," and he makes clear that this language, the expanded builders' language, "contains those other sentences 
as well-but is this having a mastery something that happens while you are uttering the sentence?" We shall return to this concept of mastery because it will prove to be one of the clearest points of intersection between art and language. But before progressing to the discussion of the dimensions of art perfectly corresponding to, and thus in fact constituting, stylistic language-games, there remain a few more characteristics of language-games that must be identified first.

In section 22 of Philosophical Investigations Wittgenstein sounds a cautionary note concerning the unwitting transgression of the limits of a language-game. He observes that although Frege believed that every assertion could be characterized, or written in the form, "It is asserted that such-and-such is the case," in fact, " 'that such-and-such is the case' is not a sentence in our language," thus suggesting that the attempt to characterize assertion generally in a context-free form is in an interesting way impossible. Assertion, after all, takes place as an action embedded within the game, and its attempted general characterization occurs, naturally, above and beyond it. Indeed, we are here inclined to transgress the limits-the context - that assure the intelligibility of the assertion in the first place. "So far," Wittgenstein adds, "it is not a move in the language-game." Still, illegitimate moves in a language-game are only part of Wittgenstein's concern here. If we claim, as a further manifestation of a desire to give the act of propositional assertion a general formulation, that by saying, "Such-and-such is the case," we really mean, "It is asserted: such-and-such is the case," then the "words 'it is asserted' simply become superfluous." And this gives us an example of a linguistic maneuver that looks like a legitimate move but is in fact vacuous or, indeed, superfluous. Such a prefatory phrase, dropped in from above, is again not a move in the game. In short, on the linguistic side of the analogy between language and art for which we have been laying the foundation, there are illusory "moves," or formu- 
lations, that look good but in fact are empty. And as we shall see below, there exists a direct parallel in art.

The final characteristic of language-games of which we must make note concerns not a sensitivity to but rather the nature of their expansion or growth. In section 23, referring to the multiplicity of kinds of sentences, Wittgenstein observes that this multiplicity "is not something fixed, given once for all; but new types of language, new language-games, as we may say, come into existence, and others become obsolete and get forgotten." Such growth is probably best characterized as "organic," which underscores the fact that the individuation of games is by no means a simple or predictable matter, and that individuation, insofar as it is called for at all, will proceed in different ways and according to different criteria in individual cases. And as we shall see, stylistic border disputes in the arts indicate that individuation is not a simple or straightforward matter in the analogous aesthetic contexts in which "organic" stylistic expansion occurs. ${ }^{13}$ Moreover, this way of putting it shows one of the conceptual interrelations between the notions of language-games and "forms of life" as they appear in Wittgenstein's philosophy generally. ${ }^{14}$ But the important point

13. Here again see J. F. M. Hunter, "'Forms of Life.'”

14. That interrelations exist between the notions of "forms of life" and "language-games" does not of course entail that they are identical. For a discussion of games played with language, as "an obvious transition between childhood games and literature," see Laurence Lerner, The Frontiers of Literature (Oxford: Basil Blackwell, 1988), pp. 191-95. For an instance of a rule being first made explicit and then broken, bent, or altered as an artistic gesture, see the discussion from which this passage is taken: "Play sticks to the rules, play breaks the rules. Sticking to the rules of the game is what licenses the flouting of more serious rules. Simply to utter a row of incomprehensible syllables would not constitute much of a release, since it is so cheaply purchased: it offers no kind of threat to serious thinking" (Lerner, Frontiers, p. 20o). For an analogous discussion in the visual arts, see Kirk Varnedoe, A Fine Disregard: WhatMakesModernArt Modern (New York: Abrams, 199o), in which Varnedoe's governing insight is the fine, i.e., innovative, expressive, cultivated, and his- 
within the present context, that is, in establishing the expectations for what an account of artistic style will look like when elucidated as an analogue to language-games, is that languagegames can grow, as do cities, in different ways at different times. In section 18, Wittgenstein shows that the concept of "completeness" is in fact alien to a discussion of language-games. Was our language, he asks, complete before the symbolism of chemistry or the notation of the infinitesimal calculus? There is, of course, nofixed number of houses and streets definitionally prerequisite for a town to be a town. Indeed, Wittgenstein makes this illuminating simile explicit in a well-known passage, saying, "Our language can be seen as an ancient city: a maze of little streets and squares, of old and new houses, and of houses with additions from various periods; and this surrounded by a multitude of new boroughs with straight regular streets and uniform houses." ${ }^{15}$ As we shall also see, artistic styles are similarly organic, completeness is foreign to them (and thus the specific conditions for their establishment are equally resistant to quantification), and they are, sometimes like medieval villages and sometimes like LeCorbusier's design for the razing and rebuilding of Paris, sites for multifarious developments.

\section{Style, Coherence, and Artistic Limits}

It seems clear that the multiplicity of language-games is itself crucial to an understanding of how they are meant to be employed within the philosophy of language, and in section 24 of Philosophical Investigations Wittgenstein says, "If you do not keep the multiplicity of language-games in view you will perhaps be

torically progressive disregard for the rules (in which the breaking of an old rule is coincident with the making of a new one).

15. For a discussion of Wittgenstein's use of the metaphor of language as a city, see Robert John Ackermann, Wittgenstein's City (Amherst: University of Massachusetts Press, 1988). 
inclined to ask questions like: 'What is a question?' "16 This remark is made following the list of language-games in section 23, which he prefaces by saying, "Review the multiplicity of language-games in the following examples, and in others." His intent is, of course, to illustrate the practice of looking at actual diversity instead of thinking about illusory uniformity. As a way of moving the discussion from language to art, we might first find examples in the arts analogous to Wittgenstein's multifarious list of language-games.

Although a very great number of such cases could be described, I suggest only a few for each entry on the list from section 23:

1. "Giving orders, and obeying them." In music, we make a certain aspect of a military march salient if we liken it to the giving of orders. And to march in step is to obey the beat if not the letter, of the rhythmically given order. In literature, a far more detailed case could be developed through a close reading of Henry James's notebooks, in which he gave himself "orders," like literary prescriptions, which in very many cases he followed later in the tales and novels.

2. "Describing the appearance of an object, or giving its measurements." The Rouen Cathedral series of Claude Monet, in which the subject remains constant but the presentation of it changes under varying lighting conditions, is such a description of appearance. One might think of the entire Dutch seventeenth-century still-life school as exemplifying and then organically expanding this move. ${ }^{17}$ Visual art rarely "gives mea-

16. Although recognizing multiplicity can erode our confidence in questions of the "What is a question?" type and promote in us a healthy disrespect for essentialistic uniformity, acknowledging multiplicity certainly need not commit us to a subjective relativism about what may and may not be taken as a question, an answer, or the possibility of an answer. In this connection, see Renford Bambrough, "Unanswerable Questions," Proceedings of the Aristotelian Society supp. vol. $4^{\circ}$ (1966): 151-72.

17. For the definitive argument that this entire movement was the exacting pursuit of appearances rather than the encoding of readable "meanings" char- 
surements" but it does most assuredly depict dimension, examples being the sublimity of Alpine scenes, and the monumentality of Nature generally, in nineteenth-century Romantic painting. Describing the appearance of an object is also, of course, a game that is played throughout literature; we will consider particular cases of this, particularly where the descriptions of domestic interiors and of character function in very similar ways, below.

3. "Constructing an object from a description (a drawing)." One here thinks instantly of the famous Dürer illustration of the rhinoceros,$^{18}$ full of inaccuracies but, indeed, constructed from descriptions. Some of Leonardo's sketches for inventions, such as the helicopter, are similarly drawings of objects (in this case nonexistent) from his own prior descriptions. If we greatly expand the game to include "constructing a sense of a person's character and motivations," then again this game is played throughout fiction, as in the example of Henry James's character Peter in "The Tree of Knowledge," discussed in Chapter 5 .

4. "Reporting an event." Narrative paintings of course provide countless examples, but in medieval painting the depiction of scenes of martyrdom serve nicely, as do many other forms and genres such as the Bayeux Tapestry reporting the details of battle, Trajan's column reporting Roman political events, and every Madonna and Child depiction. Political journalism iis a nonartistic version of this language-game; when this game is represented in fiction, it itself is "reported" on, within the context of a work of art. Of course here too countless cases are readily available in fiction; we will return to some in detail in James's "The Author of Beltraffio."

5. "Speculating about an event." David's Death of Marat depicts an event the painter did not witness, and is thus specu-

acteristic of the southern art of the period, see Svetlana Alpers, The Art of Describing (Chicago: University of Chicago Press, 1983).

18. See Norman Bryson's discussion of this case in Vision and Painting: The Logic of the Gaze (New Haven: Yale University Press, 1983), pp. 22-25. 
lative. More recently, many of Cindy Sherman's photographs of herself in multiple guises in divergent contexts can be construed as speculations on selves that might have been. In a different way, works of art and architecture can prompt speculations about events; consider Egyptian pyramids or Roman aqueducts. In fiction, the entire genre of the historical novel defines the context within which such speculation becomes possible.

6. "Forming and testing an hypothesis." One might say that the Impressionist movement, when it moved out of the studios and into the fields, was a painterly response to a hypothesis about the immediacy of vision and human perception; ${ }^{19}$ the test was conducted, with ultimately successful results, with pigment on canvas. ${ }^{20}$ One might say that artists test hypotheses about themselves in their capacity for creation within specific contexts as well, for example Gaugin's excursions to Tahiti or Stravinsky's to Hollywood. In ethics, we-to cast the matter only slightly oddly-form and test hypotheses in the process of coming to understand another person; this process becomes artistic when it is depicted and simultaneously commented on in fiction, as we shall see it done in James's "The Figure in the Carpet."

7. "Presenting the results of an experiment in tables and diagrams." Although tables and diagrams admittedly seem remote from artistic contexts, the presentation of experimental results is common throughout the arts. Arnold Schönberg's early twelve-tone works, Karlheinz Stockhausen's early uses of tape-splicing techniques in the studio, and John Cage's use of aleatory compositional procedures will serve. In a different way, Jackson Pollock's "psychoanalytic" paintings can be seen

19. See Richard Shiff, Cezanne and the End of Impressionism (Chicago: University of Chicago Press, 1984).

20. On the counterintuitive yet accurate placement of the model of scientific experimentation within artistic creation, see John Gilmour, Picturing the World (Albany: State University of New York Press, 1986). 
as the results of a psychological experiment; Marcel Proust's novels can also be seen as a presentation of the results of a psychological experiment, one in which a conception of the self, its history, its continuities and discontinuities, and its engagements are created in the observation, in the self's literary depiction.

8. "Making up a story; and reading it." The morally deep visual narratives of Nicolas Poussin are in a sense "made-up"; "reading" a story can be reading a story, or painting a story, or acting out a story. "Reading" a music-dranna (of any sort) entails every sort of reading except reading as narrowly construed, yet reading it is. Children's books are made up, and then illustrated; in a more sophisticated but still linguistically analogous way, Hogarth's engraving series, as moral stories invented and depicted, follow the same pattern. Of course, all of these cases are more examples of, rather than parallels to, Wittgenstein's language-game: they were aesthetic games to begin with.

9. "Play-acting." The eighteenth-century convention of English portraiture, in which subjects are depicted in costumes of renote times and places in order to associate ideas from apparel to the subject, or to reveal some aspect of the character of the subject, serves as a visual analogue. The distinction between oratorio and opera is also of use here; a performer plays the role of the character in the latter and not in the former. Of course, theater and film are perhaps the most obvious artistic exemplifications of this kind of language-game, but they do certainly appear in fiction. One case is James's character Mrs. Mallow, the wife of the artist who is (probably, as we shall see) playing a part with respect to what she does and does not know about Mr. Mallow.

10. "Singing catches." In learning to sing catches, or when participating in the singing of a round, what one learns is analogous to learning a verbal language of a technical discipline, for example, the terminology and nomenclature of harmonic 
analysis. In singing a round, one learns, through making moves in the musical game, to come in at the right part, and once having successfully made the entrance (after a number of erroneous attempts), one learns to persist in one's own melody, despite what others are singing. The singing is indeed rulegoverned, or at least stands in correspondence to rules, but one plays the game first, and one comes to hear what to do--what moves to make-through repeated trying and correcting, through action. And of course, even more directly than in the case of speech, the voice is used instrumentally.

1 1. "Guessing riddles." Works that represent riddles directly, such as Poussin's Arcadian Shepherds, the riddle of the Sphinx, and the entire genre of the spy novel spring to mind. But these are cases of riddles inside the narrative or pictorial context of the work itself. Beyond this, in many cases the perceiver of the work is placed in the position of the riddle-guesser, for example, the emotive content of the much-speculated-about enigmatic smile of the Mona Lisa, the Op-movement (as in "What is this one supposed to do?"), and the experience of coming face-to-face with a perfectly portrayed Campbell's soup can. And beyond this, many works seem to exude an undeniable yet inexplicable sense of depth and mystery, for example, Rothko's chapel paintings or, in very different ways, the film noir photographic technique or the control of light in early Romanesque churches. Of course the phrase "guessing riddles" aptly fits more than one character in "The Figure in the Carpet," a literary language-game to which we shall also return.

12. "Making a joke; telling it." When Goya was commanded to paint the portraits of the royal family, as a way of personally expressing his views of the family he portrayed them with stupefied facial expressions. And to the extent that those bovine gazes were discussed at all, they were understood as the best his technique would allow; that is, they were not seen as the deliberate moves in a game that they in fact were. In short, a visual joke was made and told. In a different way, the archi- 
tectural jokes of Giulio Romano are clear to someone who knows the language-and the range of possible gestures within the visual vocabulary--of the Renaissance style of facade decoration. The rapidly descending figure that opens Stravinsky's History of a Soldier is undeniably comedic in its timbre as it descends into the lowest register and in its instrumentation. Examples of this language-game in literature are simply too numerous to mention.

13. "Solving a problem in practical arithmetic." If a bridge, as a work of architecture, can be a work of art, then the problems solved in, for example, Benjamin Baker's Forth Bridge provide a perfect illustration. ${ }^{21}$ Of course, the solution of countless problems of structural engineering precede any architectural construction; cases such as the development of the flying buttress of the Gothic style or the employment of the cantilever in Frank Lloyd Wright's Falling Water render such accomplishments more visible to the critical eye. Another illustration can be found in the solving of problems of harmonization that occur in a fugue, where a composer desires to make not only correct but rather the best possible moves within the fugue's thematic logic.

14. "Translating from one language into another." Throughout his work, but perhaps most notably in the string quartets, Bartok incorporated Hungarian folk themes, or fragments of those themes, into the much larger-scale compositional structure of the quartet. Simply put, he translated motifs from one idiom into another. Mussorgsky's Pictures at an Exhibition is a different kind of translation, this time across the arts. In a

21. For the detailed discussion of these contextually situated problems, see Michael Baxandall, Patterns of Intention (New Haven: Yale University Press, 1985), pp. 12-40. See also in this connection Mary Mothersill's discussion of El Greco and the Count Orgaz case, in which it is made clear that the context of the lines of the painting determines the aesthetic significance of those lines, in Beauty Restored (Oxford: Clarendon Press, 1984), chap. 11, "The Concept of Beauty: Aesthetic Properties," pp. 323-66. 
similar way Debussy captures in translation an aspect of nature in La Mer. Rilke's Letters on Cezanne ${ }^{22}$ can easily be construed as yet another kind of translation, in this case the visual to the verbal. Reversing the direction of translation, a filmmaker begins with a script and ends with its visual realization. Further, within music, a full orchestration of a piece originally composed for piano or small ensemble and the reduction to a piano score of an orchestral piece are strikingly like translations. Moreover, debates concerning the quality and accuracy of such transcriptions mirror perfectly debates concerning the quality and accuracy of translations.

15. "Asking, thanking, cursing, greeting, praying." Charles Ives's Unanswered Question is aptly titled. The brass ask one question over and over, and receive increasingly full but ultimately unsatisfying "answers." Thanking has a definite place within the musical structure of the mass, as well as within the visual context of, for example, late medieval painting. In a very different way, sculptural works commissioned for commemoration, for example, of Winston Churchill, are sculpturally embodied gestures of thanks. Depictions of cursing, as might be imagined, are common among illustrations of Dante's Divine Comedy; cursing also occurs in a vividly literal way in the more authentic variants of blues music. Greeting, in the arts, is perhaps best exemplified in architecture; it is difficult to think of a clearer case than that of the enveloping curved "arms" of the colonnade of the courtyard of St. Peter's Cathedral. Similarly, almost any successful portico in secular architecture achieves the same effect, if perhaps not so forcefully. Praying can be found in the arts in a number of very different ways; it is given a context and is encouraged by the traditions of interior design in sacred architecture, it is encouraged or visually depicted in painting, and it is given occasion again within the setting of the

22. Rainer Maria Rilke, Letters on Cezanne, trans. Joel Agee (New York: Fromm International, 1986). 
mass. Moreover, although this is not the place to pursue the topic, some would argue that there are phenomenological interconnections between religious and aesthetic experience quite generally.

Wittgenstein assembled this list to remind us that those who insist that there are really only three fundamental kinds of sentence, assertion, question, and command, are wrong, that there are in fact "countless kinds: countless different kinds of use of what we call 'symbols', 'words', 'sentences'." And, like the growth of a city, "this multiplicity is not something fixed." At the end of the list Wittgenstein remarks, "It is interesting to compare the multiplicity of the tools in language and of the ways they are used, the multiplicity of kinds of word and sentence, with what logicians have said about the structure [and essence] of language." and he includes among these logicians the author of the Tractatus Logico-Philosophicus. After even a brief review of the analogous language-games in art, it is equally interesting to compare this multiplicity with what aestheticians have said about the structure and essence of art. We saw Wittgenstein's remark concerning the importance of keeping the multiplicity within the philosophy of language in clear view; failing to do so, he warns, will generate "questions like: What is a question?" where what is asked for is a general account that captures the essence of a question quite apart from the context within which the specific question arises and quite apart from the aim and function of that question. We might also ask, if we fail to keep artistic multiplicity in clear view, questions such as "What is a painting?" which may mean "What [essentially] must every painting have to be a painting?" or "What [instrumentally] must every painting in fact do to be a painting?" and expect an answer that is "correct" regardless of any particular context. And even if questions such as "What is art?" are generally regarded as being hopelessly general, questions such as "What is music?" "What is film?" "What is architecture?" and so on often are not, but the latter questions attempt to 
operate above and beyond a language-game in which intelligibility is ensured, just as does the question "What is a question?" Tools from a toolchest do not have a use outside the specific contexts within which they are employed; to ask for such a definition is to imply that they are used generally, which is an obvious absurdity. Cities do not grow and change generally; they do so on specific sites, and to suggest or imply anything else is equally obviously absurd. If these analogies are helpful in understanding language and if language is in turn helpful in understanding art, then we should be wary of aesthetic questions possessing the same generality and potentially the same absurdity. But this brings us to still another characteristic of language-games, their power to make visible, within restricted contexts, the limits of coherence, and we should now pursue the parallel in art.

We saw in the preceding section how easy it is to transgress the limits of a game unwittingly, to attempt to make a linguistic move not possible within circumscribed limits. In section 27 Wittgenstein reminds us of this, looking back to both the basic and the expanded builders' languages and saying of them that "there was no such thing as asking something's name. This, with its correlate, ostensive definition, is, we might say, a language-game on its own." In the arts, it is, even if difficult to say why, remarkably easy to recognize an analogous transgression. If in music we use parallel fifths to harmonize a chorale melody, that move will be instantly recognizable as a mistakewithin this style. It is not simply a misplaced dissonance and thus a "simple" mistake; it is in fact too consonant. But listeners will hear that passage as out of place, as, indeed, a move not available to that game. Similarly, if an architect places a gothic window next to a romanesque, then places a series of oculi between a row of classical columns, and then supports an outer wall with a single gothic buttress countered by a baroque staircase on the opposite side, we know at a glance that the result is, quite simply, visually incoherent. Each of the architectural 
elements, as part of a larger design-vocabulary, implies the existence of other possible moves consistent with and afforded by that vocabulary, but these are, in this imaginary case of architectural incoherence, not the moves made. A range of possible moves is implied, analogues to "Hand me a slab," "Hand him a slab," "Hand her two slabs," and so on, but instead of such possible moves we get the visual equivalent of what is referred to in some quarters as a word salad. This is of course not to say that the demands of coherence preclude growth. We can see in retrospect the progressive visual invention, the clear expansion of a style in a manner that does not strain coherence, in the classical orders. The rather stern Doric yields to the softer Ionian, which in turn is expanded-but expanded within the same visual language-by the Corinthian. And indeed, like the synthesis of a few resident linguistic possibilities of a given game, ${ }^{23}$ there followed the composite order. Similarly, postmodern architectural design incorporates sectors of various, previously established vocabularies, but does so, at least in the successful cases, in ways avoiding incoherence of the type imagined above; that we can tell the difference between the suc-

23. For a succinct example of the successful merger of two initially separate language-games, in which the linguistic moves of the synthesized game become themselves naturalized, see G. P. Baker and P. M. S. Hacker, Wittgenstein: Understanding and Meaning (Chicago: University of Chicago Press, 1980), p. 98: "Compare, e.g., the penetration of the hydrodynamic terminology into electrodynamics in virtue of the complex analogies between the behaviour of fluids and electricity. We all speak of 'electric current' (or of electricity as 'current'); and it is immediately intelligible to characterize voltage as electrical pressure or amperage as the rate of flow of electricity." For an analogous case in art, see Kirk Varnedoe on Rodin, where he discusses in detail how Rodin made in his sculpture new moves of completion and incompletion in the interest of generating new sculptural meanings, in A Fine Disregard, pp. 127-141. And for a clear statement, visually supported, of the significance of use within a delimited context for the determination of artistic meaning, see pp. 178-80. See also Richard Wollheim's discussion of Adrian Stokes, particularly on gesture and expression, in $\mathrm{On}$ Art and the Mind (Cambridge: Harvard University Press, 1974), esp. pp. $321-34$. 
cessful cases and the others so quickly is itself further, implicit endorsement of the analogy with language.

Naturally, the adjudication of the legitimacy of all moves made within stylistic languages, and specifically in merging or synthesizing such languages, is often controversial; for example, one can debate whether or not Gershwin ought to have merged musical idioms as he did, whether classical images ought to be used in advertising, whether Bach ought to be used as a basis for jazz improvisation, whether advertising icons, such as Brillo boxes or Campbell's soup cans, ought to be elevated to the status of objets d'art, whether Rauschenberg ought to have invented the antimove by erasing de Kooning, and so on. But in each of these cases, what is debated is the legitimacy of the move and whether or not the move is in fact generated within the style's vocabulary or what that style allows vis-à-vis logical expansion. In short, the very conception of artistic purity is elucidated in terms of what is "sayable," with propriety, within the boundaries of a style, just as debates about coherence and stylistic integrity are debates about the locations of the limits of artistic language-games and the justifiability of the mergers of such games.

The builders show that they understand a move in their game when they see how the linguistic move is meant to operate, or when they see its aim and function. When an audience member hears that a pianist displays the limits that the composer has circumscribed in the theme, and then when he hears, or beyond that comprehends, that the first variation is a move or set of moves made possible by that theme, mere brute perception becomes musical understanding. When he next hears that the second theme is an exploration of melodic, harmonic, or rhythmic possibilities generated by the initial theme and its first variation, its first controlled expansion of the language, he then understands that further dimension of the composition as well. Similarly, we can recognize the language to which "Girder!" might well be quite coherently added, and we can imagine how 
the builders would quickly come to use it. In a parallel fashion, many are able to recognize at a glance that a heretofore unseen painting is a painting by Cezanne by recognizing Cezanne's characteristic moves-particular moves we have not seen executed before but which nonetheless quite clearly belong to his style. In the same way one is able to imagine how Cezanne might have portrayed the exterior of one's own house with a certain volumetric or block-like aspect with distinctive shades of blue, green, and a range of colors in between. Moreover, recognizing the appropriateness of a move within Cezanne's style made by another painter is recognizing Cezanne's influence on that painter. And that it is a stylistic language-game we are perceiving is rendered further evident by the fact that we can recognize unexpected affinities between radically divergent styles, for example, between primitivism and modern art, as a function of seeing first the inner coherence of each style and then seeing that moves made within these styles, although irrevocably different for their differing contextual placements, are nevertheless in one specific aspect or another strikingly alike. And the appropriation of language-games for aesthetic purposes is still further warranted by the fact that we can, as we do indeed of ten describe it, "learn the language" of a given artist. Modigliani uses hard black lines to depict faces; Seurat uses concatenations of points of color. Debussy uses parallel harmonies and chords of the ninth, Stravinsky uses modernistic-yet-primitive rhythms. In these cases, one can very quickly recognize that what one is seeing or hearing is characteristic of that artist's style. One has learned, or at least learned to recognize, that artist's visual or auditory language.

Another centrally important characteristic of languagegames in Wittgenstein is, as we saw above, their self-sufficiency or internal containedness, which is to say that the moves possible, the limits of the expressible within a language-game, are determined from within. To pursue this characteristic in art, 
the case that most readily presents itself is that of serial or twelve-tone musical composition.

Traditional harmony possesses, as a centrally significant move, the establishment of key centers, such that a given work, movement, section, or passage is in a particular key. The first move of a serial composition is to repudiate key-centeredness, or traditional tonality, by requiring moves that intrinsically prevent the establishment of a key center. Very simply stated, a composer begins by defining a "row," a sequence of all twelve pitches of the chromatic scale, usually arranged in such a way to avoid implying a key center, which is usually accomplished by avoiding rising or falling intervals of a fourth or fifth. This row, intrinsically ambiguous harmonically in that it does not imply a tonic, is then permutated for the generation of other possible moves; these include playing the row backward (the retrograde row), upside-down (the inverted row), or both (the retrograde-inverted row). Already, although no real music has been composed, the composer has located within a compositional set of possibilities a set of moves generated and legitimated internally - and excluded a far larger set of moves, those associated with traditional harmony, which are by definition beyond the realm of the intelligible within this compositional system, because, as this is serial composition, each pitch must be employed in sequence. An entire row, if started, must be exhausted before any pitch may be employed a second time; thus one cannot simply choose desired pitches and establish a key. This language began with Schönberg, but as it evolved in the hands of Berg, Webern, the followers of the Second Viennese School, and up to and beyond Boulez in more recent years, it was both explored for its expressive range and intrinsic potentialities and expanded through the gradual subjection to serial ordering of other compositional parameters, such as dynamics, instrumentation, timbre, and more recently, within the context of the electronic studio, left-to-right and foreground- 
to-background sonic placement. Thus the composer first establishes the compositional language-game, the initial vocabulary, then expands the ranges of moves within it through recombinations that are themselves determined by the initial row, and then-having set the bounds of the "sayable" within this musical language not from without but from within through establishing the intrinsic combinatorial reach of the available vocabulary-begins to create a serial work.

From the listener's point of view, numerous phenomena occur which are perfect analogues to the experience of the hearer of a language-game. The piece can sound cacophonous to those who have not yet, in any sense, learned the language-just as "Slab!" is an inarticulate shriek to a nonbuilder. But if one is given the row, and then plays it at the piano a number of times (again, not the composition itself, but merely the row that generates the possible moves utilized within the composition) and then listens again, what was seemingly utterly incoherent begins to take on an elusive kind of sense. If one then plays the row at the piano in its retrograde, inverted, and retrograde-inverted forms, and listens again, incoherence is increasingly replaced by intelligibility. One has carried out the musical equivalent of not just gazing uncomprehendingly at the builders from afar but of working with them so that the aim and function of their language becomes comprehensible. And as one might follow the incremental expansions to the builders' language, so one can follow, through the integration of the dynamic range into serial ordering, the development and consequently expanded expressive range, of the serial technique. And, as is true with the language-game, at no point does one go outside the system to render it comprehensible, nor at any point on the way from perceived cacophony to musical understanding does one ask a question concerning the general nature of organized pitch any more than one asks about the general nature of a question devoid of context. Of course, one might ask a general question about this style, specifically if it precludes authentic composi- 
tional creativity through imposing a deterministic system on a composer who would otherwise possess an unhampered free will. ${ }^{24}$ But the answer would be spelled out in particulars; for example one might examine the perfected musical microcosms created by Webern within the larger confines of serialism. This would also begin to demonstrate that the mastery of a style involves the capacity to see and to use to great effect moves that are available within the style and yet far from obvious. In any event, it is perhaps Webern's short works that demonstrate that serial composition, as an exact analogue to a languagegame, is a self-generating and self-sufficient system.

Quite beyond this single musical case, one can easily imagine countless further illustrations of the correspondence between language-games and artistic styles. In Philip Johnson's glass house one can quickly learn, within that microcosm of the modernist vocabulary, which moves are possible and which are not. In southern German baroque churches one can see quite quickly how alien a monastic darkness would be to that style. In St. Mark's in Venice, one can see some "Eastern" gestures. Indeed, St. Mark's is a very specific site for stylistic expansion through merger; the (recognition of) Byzantine influence is an instance of (the recognition of) stylistic merger. And in the paintings of Philip Guston one can see a return from an abstract language, with its intrinsic delimitations, to figuration, which brings a range of possible gestures obviously unavailable to the language of abstraction. In Anselm Keifer one sees the definition of a number of sites for expansion; these include the integration of non-oil textures, for example, that of molten metal, onto the canvas, and the heavily textured series of "books," which obscure the distinction between painting and

24. Of course, for a student of this style, the serial system can (and initially, probably should) be deterministic. But consider the great American saxophonist Charlie Parker's comment on the importance of learning the rules of harmony for improvisation, to the effect that the rules must be learned so that they can be forgotten. 
sculpture. But again, such a list could continue indefinitely; the point is that we do, as perceivers and interpreters, participate in a critical enterprise that like the learning of a specific language with its comprehended aims and functions, allows us to distinguish between the master and the novice, between the coherent and the unintelligible, between the inventive and the formulaic, between the insightful and the commonplace, between the justifiable expansion of the stylistic range and the utterly incongruous. We are also able to distinguish between the meaningful and the vacuous, the significant and the empty. But this, in connection with language-games, we must look into more closely.

Wittgenstein identified the superfluity of Frege's attempt to display the nature of assertion by inserting "It is asserted:" before the propositional claim that "such-and-such is the case." It appears that we are of ten quick to recognize analogous superfluity or emptiness in visual or musical form. In some Spanish architectural decoration, for example, one sees the repetition of the visual theme to the point of exhausting redundancy. ${ }^{25}$ One wants to say here, where indeed this expression is itself further evidence of our seeing within the context of a visual language-game ${ }^{26}$ that "the same thing is being said over and over." As we know, that we are inclined to put the matter this way need not commit us to try to describe what it is that is being said outside the work in question ${ }^{27}$ - this would indeed

25. See Roger Scruton's discussion of the Spanish Baroque or "Churrigueresque" style in the Charterhouse at Granada, in The Aesthetics of Architecture (Princeton: Princeton University Press, 1979), p. 208.

26. For an elucidation of the notion of seeing within a now-remote context, and its significance for art-historical methodology, see Michael Baxandall, "The Period Eye," in Painting and Experience in Fifteenth-Century Italy (Oxford: Oxford University Press, 1972).

27. On the ill-motivated desire to describe what it is that is "being said" in a work outside of any reference to the work in question, see my "Creation as Translation," Journal of Aesthetics and Art Criticism 46 (Winter 1987): 249-58. 
be to transgress the limits of the game. In the same way, many critics of the musical direction known as minimalism criticize it for its redundancy; it too seems to say the same thing over and over. Its defenders, of course, are quick to observe that this is indeed the point, where a single thematic gesture is made, itself suggesting the melodic and rhythmic context - the intrinsic range of melodic, harmonic, and rhythmic permutational possibilities, within which that single gesture will be very gradually transformed. In short, the defense of auditory minimalism is that this musical language is a microcosm within which we become acutely aware of incremental expansion, where the sense of each transformation is guaranteed by its thematic progenitor. This debate, as it has developed, is a debate about a stylistic language-game.

We also saw, in Wittgenstein's elucidation of the idea of a language-game, how the limits of the sayable are determined not by the imposition of some kind of external linguistic constraint or boundary but by the intrinsic reach of the collective possible moves within the game. Thus in the same way that the limits of one's visual field are not described by extrinsic demarcation from beyond that field, ${ }^{28}$ but rather by its intrinsic reach, so the limits of the expressible within a language-game are in a sense self-determined or autonomous. I believe this is one of the few junctures between art and language where this view is more widely presumed (if unarticulated) in the arts than it is subscribed to as a view describing language. Indeed, the entire range of critical discourse concerned with the depth or, by contrast, the shallowness, of a given genre or style relies on

28. See Ludwig Wittgenstein, Tractatus Logico-Philosophicus, trans. D. F. Pears and B. F. McGuinness (London: Routledge \& Kegan Paul, 1961). 5.65.641, and Peter Winch's discussion "Text and Context" in Trying to Make Sense (Oxford: Basil Blackwell, 1987), esp. pp. 22-26, in which Winch pursues the comparison between (1) the eye itself not being a "part of the visual field" and (2) the knowing subject's relation to the world that is known. 
it. This would, of course, have to be argued through particulars, and once again the list could be long. But a few cases here too will suffice to point the direction.

One might say of Vivaldi that although his instrumental music is pleasant, it is rarely deep; the range of expression within that harmonic vocabulary is intrinsically delimited in a way that precludes depth. Thus the criticism is not in this case that Vivaldi failed, for he most assuredly, as a master of that style, did not. If pressed, the same critic may elaborate by placing a contrasting case next to it, saying that although Bartok's Concerto for Orchestra is rarely pleasant, it is always deep. A critic might object to the inclusion of Norman Rockwell on a list of important American painters, saying that the interest is with artists, not craftsmen. That is, the moves of a very narrow (and in this case, naively sentimental) game are deployed over and over again, with no thought of expansion. If challenged here, that critic might point to Picasso's "Blue" period, which is admittedly sentimental, and in a respect naively so, but which is also something Picasso transcended. That early style and its intrinsic limits gave way to many later (and better) ones. Unlike Rockwell, this argument would proceed, Picasso did not fall victim to craftsmanly complacency. And indeed, to criticize an artist for being "trapped" in a narrow style is to register a desire for that artist to locate and begin work on sites for expansion. In a similar fashion, to claim that a style is now exhausted is to claim that all the moves housed within it have become excessively familiar and hence that inside this game it is now impossible to "say" anything new. This was in fact said of serial music a number of times, and each time another parameter was brought into the serial vocabulary thus expanding the limits of that language. Artists can also express the feeling that although a language may not have been exhausted in the preceding sense, a master of that language has made contributions within it and has seen nonobvious moves and made them, in a way beyond the capacity of the artist in question. This feeling 
is often musically expressed by jazz musicians playing in the modern style by "quoting" (itself a revealing locution) a passage of Charlie Parker's at a difficult point in the harmonic terrain, thus acknowledging the depth and insight of Parker's move at that juncture. This brief list of examples can extend into architecture in controversial cases such as the addition to Frank Lloyd Wright's Guggenheim Museum and whether or not it is perfectly consonant with the visual language of the main structure. This case involves disputes over both the appropriateness of the expansion of a stylistic language and the resultant juxtaposition of stylistically incongruous buildings behind the addition; whether, in short, those language-games are compatible such that a point of convergence can be found. An even more vociferous debate arose over Michael Graves's proposed additions to the Whitney Museum in New York. In the early design, the original structure was consumed within Graves's new postmodern full-block facade. The existing, original, internally-consistent facade was to be subsumed entirely into Graves's own visual language; in a more recent and moderate plan the stylistic consistency, and initial autonomy, of the original structure has been acknowledged. In these cases, we encounter strenuous debates concerning depth, quality, justifiability, appropriateness, redundancy, content, and so on through broad stretches of our critical vocabularies. And the internal logic of these aesthetic debates mirrors the characteristics of language-games identified by Wittgenstein.

In my opening remarks on language-games as employed by Wittgenstein in the philosophy of language, I said that only at the end of the discussion would it be possible to address the question of whether or not "language-games" would prove to be trivial exercises, or in the final analysis "only a game." Whatever the ultimate answer to that question, it seems clear that if employing the language-game strategy within aesthetics can yield at least provisional insight into problems of artistic coherence, expansion, invention, expressive limits, intelligibility, 
mastery, exhaustion, depth, stylistic integrity, the cohesion of materials and the like, and if it can lend at least some clarity to our view of how artistic meaning arises within contexts and remind us of the multiplicity of artistic meanings - or aims, functions, and uses-then the value of the language-game strategy seems assured; some mist enshrouding the concept of artistic meaning has been cleared. And if further consideration of the characteristics of a language-game leads to an awareness of the perfectly analogous characteristics of an artistic style, then to pursue the larger analogy between language and art is by no means just a game. Also, of course, to remove the central impediment to the "clear vision" of language Wittgenstein initially spoke of, that is, the "general notion of the meaning of a word," is also to remove the analogical basis for the general notion of the meaning of a work of art. And concerning limits, it was in his early philosophy, in which a concern with linguistic limits was nearer the surface of the text, that Wittgenstein said, "The limits of language... mean the limits of my world." ${ }^{29}$ Even if we now know that the limits are, from the very nature of the diverse phenomena under investigation, perennially in flux, if we have reason to accept the appropriation of language-games to artistic styles, we might say with some accuracy that the systematically fluctuating limits of stylistic language-games are, taken in toto, the limits of the art world. The varieties of meaning contained within those limits, however, are best illuminated not directly by the notion of language-games, but rather by the related-but different-notion of a form of life.

29. Tractatus Logico-Philosophicus, 5.62. 